\title{
Nano-CL-20/HMX Cocrystal Explosive for Significantly Reduced Mechanical Sensitivity
}

\author{
Chongwei An, Hequn Li, Baoyun Ye, and Jingyu Wang \\ School of Chemical and Environmental Engineering/Shanxi Engineering Technology Research Center for Ultrafine Powder, \\ North University of China, Taiyuan, Shanxi 030051, China
}

Correspondence should be addressed to Hequn Li; lhq6371630@163.com

Received 8 December 2016; Revised 5 January 2017; Accepted 10 January 2017; Published 29 January 2017

Academic Editor: Jean M. Greneche

Copyright (C) 2017 Chongwei An et al. This is an open access article distributed under the Creative Commons Attribution License, which permits unrestricted use, distribution, and reproduction in any medium, provided the original work is properly cited.

Spray drying method was used to prepare cocrystals of hexanitrohexaazaisowurtzitane (CL-20) and cyclotetramethylene tetranitramine (HMX). Raw materials and cocrystals were characterized using scanning electron microscopy, X-ray diffraction, differential scanning calorimetry, Raman spectroscopy, and Fourier transform infrared spectroscopy. Impact and friction sensitivity of cocrystals were tested and analyzed. Results show that, after preparation by spray drying method, microparticles were spherical in shape and $0.5-5 \mu \mathrm{m}$ in size. Particles formed aggregates of numerous tiny plate-like cocrystals, whereas CL-20/HMX cocrystals had thicknesses of below $100 \mathrm{~nm}$. Cocrystals were formed by $\mathrm{C}-\mathrm{H} \cdots \mathrm{O}$ bonding between $-\mathrm{NO}_{2}(\mathrm{CL}-20)$ and $-\mathrm{CH}_{2}-(\mathrm{HMX})$. Nanococrystal explosives exhibited drop height of $47.3 \mathrm{~cm}$, and friction demonstrated explosion probability of 64\%. Compared with raw HMX, cocrystals displayed significantly reduced mechanical sensitivity.

\section{Introduction}

Hexanitrohexaazaisowurtzitane (CL-20) and cyclotetramethylene tetranitramine (HMX) are usually used in high explosives and some propellants [1-3]. However, these materials have high mechanical sensitivity that strongly influences safety of formulas. Nowadays, as effective method of reducing sensitivity, cocrystal explosive technology is extensively developed [4]. In 2012, Bolton et al. [5] successfully grew 2/1 cocrystal of CL-20/HMX by slow evaporation of saturated 2propanol solution. Crystallographic density was $1.945 \mathrm{~g} / \mathrm{cm}^{3}$ at room temperature, and predicted detonation velocity was $100 \mathrm{~m} / \mathrm{s}$ higher than that of HMX. Due to intermolecular hydrogen bonding, impact sensitivity of cocrystal was not significantly different from that of HMX. Cocrystals have high oxygen balance of $-13.65 \%$, which is $8.03 \%$ higher than that of HMX and $2.70 \%$ lower than that of CL-20. Therefore, cocrystals were considered attractive ingredients in low-signature propellant formulations. Based on the study of Bolton et al., a series of researches were conducted on CL-20/HMX cocrystal explosive in recent years. Liu et al. [6] studied pressure-induced effects in CL-20/HMX cocrystal explosive by density functional theory with dispersion corrections. CL-20 plays significant role in electronic structure of cocrystals. Mechanical properties of cocrystal presented great anisotropy. Through molecular dynamics method and with CL-20/HMX cocrystal explosive as main ingredient, poly(ester urethane) (Estane 5703) as block copolymer, and hydroxyl-terminated polybutadiene (HTPB) as binder, two polymer-bonded explosives (PBXs) were explored by Sun et al. [7]. Stability and compatibility of PBX were good when containing small amount of Estane 5703. Zhang et al. [8] studied packing structure of CL-20/HMX cocrystal by using Hirshfeld surface and fingerprint plot from densities, packing coefficients, and molecular interaction contributions. $\mathrm{O} \cdots \mathrm{H}$ played dominant role in CL-20/HMX cocrystal explosive. Anderson et al. [9] prepared scale-up CL-20/HMX cocrystals from acetonitrile/2-propanol solution using resonant acoustic mixing.

Mechanical sensitivity can be reduced by decreasing particle size of explosives [10, 11]. Ultrafine explosive particles have advantage over larger ones in perspective of improving burning rate of solid propellants [12-14]. Nowadays, ultrafine cocrystal explosives attract scholarly attention. Using spray 
flash evaporation process, Spitzer et al. [15] prepared nanosized and submicron-sized CL-20/HMX cocrystals. Gao et al. [16] prepared synthesized nano-CL-20/HMX cocrystals by ultrasonic spray-assisted electrostatic adsorption. Qiu et al. [17] prepared CL-20/HMX cocrystal particles with mean size below $200 \mathrm{~nm}$ by bead-milling aqueous suspension of CL-20 and HMX for an hour. Alhalaweh et al. [18, 19] used spray drying method to prepare pharmaceutical cocrystals. Meanwhile, in our previous studies [20, 21], spray drying method was also employed to prepare ultrafine CL-20/TNT and nano-HMX/TNT cocrystals with low sensitivity. To obtain CL-20/HMX cocrystal explosive with low mechanical sensitivity, nano-CL-20/HMX cocrystal explosive was prepared by spray drying method. Furthermore, the present study investigated in detail morphology, size, thermal decomposition properties, impact sensitivity, and friction sensitivity of nanococrystals.

\section{Experimental Sections}

2.1. Materials. Raw CL-20 was provided by Liaoning Qingyang Special Chemicals Co., Ltd., China. Raw HMX was provided by Gansu Yinguang Chemical Industry Co., Ltd., China. Acetone (analytical reagent) was purchased from Tianjin Tianda Chemicals Co., Ltd., China.

2.2. Preparation of Nano-CL-20/HMX Cocrystal Explosive. First, raw CL-20 (2.19 g) and raw HMX (0.74 g) (molar ratio of CL-20 to HMX 2/1) were dissolved in acetone $(60 \mathrm{~mL})$ to form uniform cosolution under appropriate temperature and stirring. Second, B-290 Mini Spray Dryer was used to produce cocrystal explosive microparticles. The equipment was made in Switzerland BUCHI Labortechnik AG. Temperatures of feedstock and discharge were 75 and $55^{\circ} \mathrm{C}$, respectively. Pump rate, rate of feedstock, and flow of spray drying gas $\left(\mathrm{N}_{2}\right)$ were set at $35 \mathrm{~m}^{3} / \mathrm{h}, 5 \mathrm{~mL} / \mathrm{min}$, and $300 \mathrm{~L} / \mathrm{h}$, respectively. Finally, cyclone was employed to separate spray drying gas $\left(\mathrm{N}_{2}\right)$ and cocrystal explosive microparticles. CL-20/HMX cocrystal microparticles were collected in glass collector.

2.3. Characterization. S4800 field-emission scanning electron microscope was used to characterize particle size and morphology of raw CL-20, raw HMX, and prepared cocrystal sample. Equipment was manufactured by Hitachi Limited in Japan.

X-ray diffractometer was used to identify raw CL-20, raw HMX, and prepared cocrystal sample. It was manufactured by China Dandong Haoyuan Instrument Co., Ltd. Testing conditions included target material $(\mathrm{Cu})$ with tube voltage of $40 \mathrm{kV}$, tube current of $30 \mathrm{~mA}$, a $5^{\circ}$ start angle, and $50^{\circ}$ end angle.

Differential scanning calorimetry (DSC) was carried out with Setaram DSC 131 instrument, which was made by Setaram of France. In the test, each $0.7 \mathrm{mg}$ sample was placed in closed aluminum crucible with $30 \mu \mathrm{L}$ volume and hole in lid. Samples were measured with temperature profile of $30^{\circ} \mathrm{C}$ to $350^{\circ} \mathrm{C}$ with heating rate of $10 \mathrm{~K} / \mathrm{min}$ in nitrogen atmosphere and flow of $30 \mathrm{~mL} / \mathrm{min}$. As reference,
CL-20/HMX mixture with the same molar ratio was tested under the same conditions.

Raman spectroscopy (Raman) was performed to explore causes of formation of cocrystals using equipment manufactured by Bio-Rad Co., Ltd., USA. Raman excitation light was provided by $532 \mathrm{~nm}$ line of argon-ion laser, and $0.5 \mathrm{~mW}$ power was used for all measurements. For each sample, spectrum was obtained by averaging 20 scans with measurement time of $5 \mathrm{~s}$ per scan.

Perkin Elmer Spectrum 100 Fourier transform infrared spectroscopy (FT-IR) spectrometer was used to confirm mechanism of cocrystal formation. FT-IR equipment was made by Perkin Elmer in US. Samples were carried out in $\mathrm{KBr}$ pellet by mercury-cadmium-telluride detector at stand-off distance of $5 \mathrm{~m}$ using mid-IR supercontinuum light source. Samples were measured in $4000-400 \mathrm{~cm}^{-1}$ wave number range with $1 \mathrm{~cm}^{-1}$ resolution.

ERL type 12-drop hammer apparatus was used to conduct impact sensitivity test according to GJB-772A-97 standard method 601.3 [22]. Testing conditions consisted of drop weight of $2.500 \pm 0.002 \mathrm{~kg}$, sample mass of $35 \pm 1 \mathrm{mg}$, and relative humidity of $50 \%$. Test results were represented by critical drop height of $50 \%$ explosion probability $\left(\mathrm{H}_{50}\right)$.

WM-1 pendulum friction apparatus was used to test the friction sensitivity based on the GJB-772A-97 standard method 602.1 [22]. Experimental conditions are shown as follows: pendulum weight, $1.5 \mathrm{~kg}$; swaying angle, $90^{\circ}$; pressure, $3.92 \mathrm{Mpa}$; sample mass, $20 \pm 1 \mathrm{mg}$; and test number, 25 . Friction sensitivity is expressed as explosion probability $(P)$.

\section{Results and Discussion}

3.1. The Size and Morphology of Cocrystal Particles. Figure 1 shows scanning electron microscopy images of raw CL-20, raw HMX, and CL-20/HMX cocrystal explosive. As shown in Figure 1(a), raw CL-20 particles are spindle-shaped, and particle size is $30-300 \mu \mathrm{m}$ with uneven distribution. As presented in Figure 1(b), raw HMX sample particles are polyhedron, and average particle size is $100 \mu \mathrm{m}$. Figure 1(c) displays sphericalshaped microparticles with size ranging from $0.5 \mu \mathrm{m}$ to $5 \mu \mathrm{m}$. As indicated in Figure 1(d), CL-20/HMX microparticles are composed of numerous tiny cocrystals, which are platelike in shape. Plate-like cocrystals have thicknesses below $100 \mathrm{~nm}$.

3.2. XRD Analysis. XRD was used to evaluate raw CL-20, raw HMX, and CL-20/HMX cocrystal explosive. Figure 2 presents observed patterns. By using MDI Jade 9 and PDF 2009 software, crystal form of raw CL-20 was identified as $\varepsilon$-type (PDF\#00-050-2045), and raw HMX exhibited $\beta$ type crystal form (PDF\#00-045-1539). As shown in Figure 2, all diffraction peaks of raw HMX appeared in CL-20/HMX cocrystals pattern. However, diffraction peaks of raw CL-20 did not appear in pattern of CL-20/HMX cocrystal explosive at $12.5^{\circ}$ and $13.8^{\circ}$. Compared with patterns of raw CL-20 and raw HMX, at $11.4^{\circ}$ and $13.2^{\circ}$, respectively, new diffraction peaks appeared on CL-20/HMX cocrystals pattern. These XRD patterns are similar to research results of Qiu. Changes 


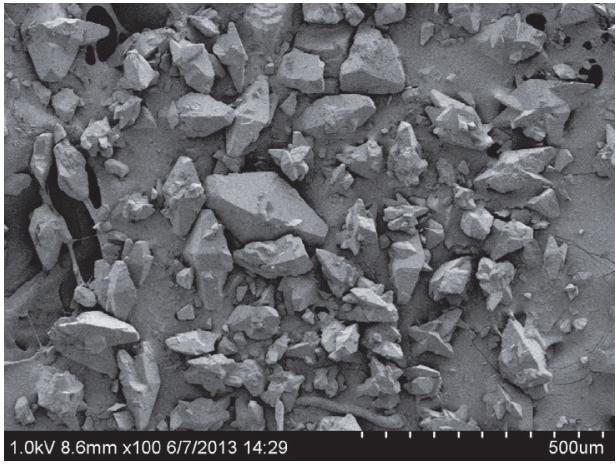

(a)

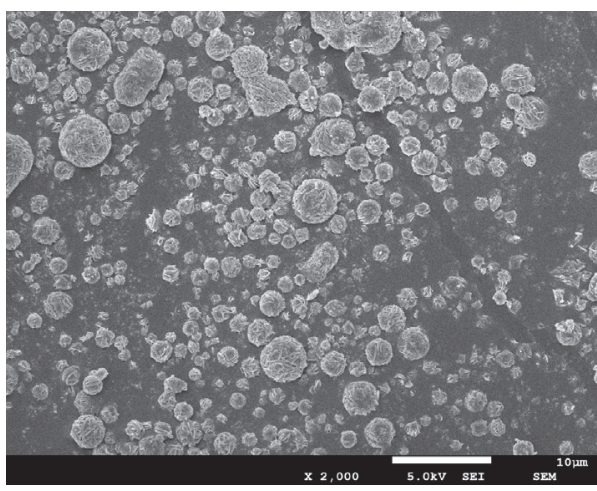

(c)

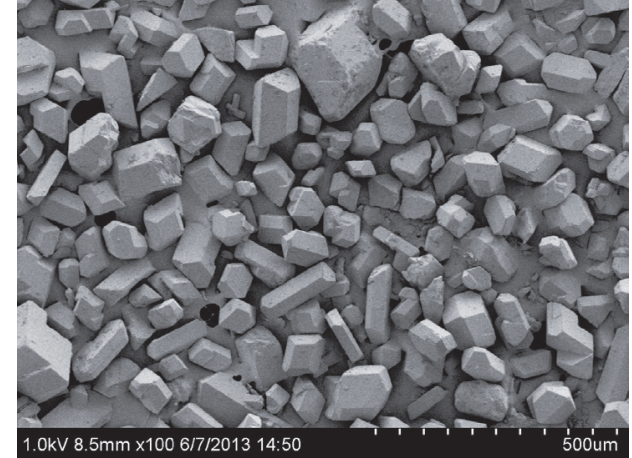

(b)

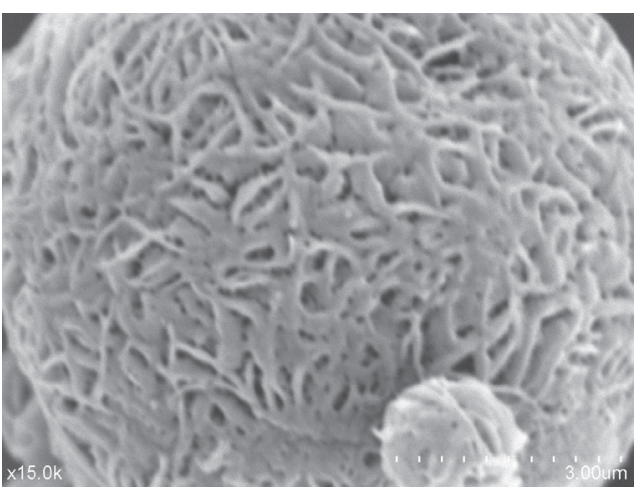

(d)

Figure 1: SEM images of explosive samples: (a) raw CL-20; (b) raw HMX; and (c, d) CL-20/HMX cocrystal explosive.

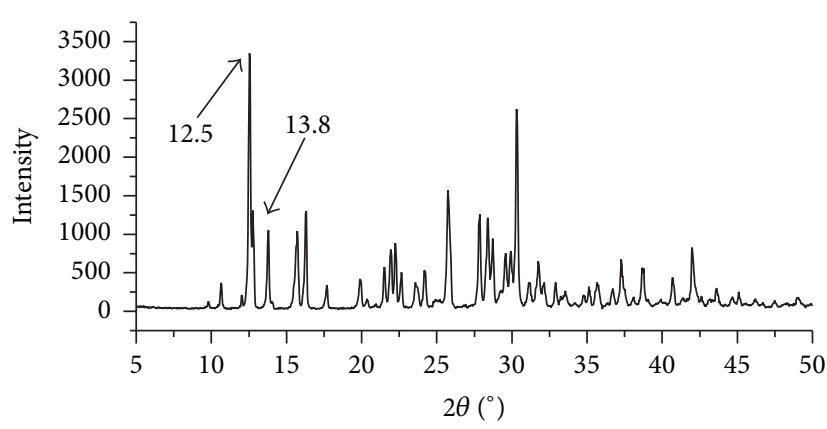

(a)

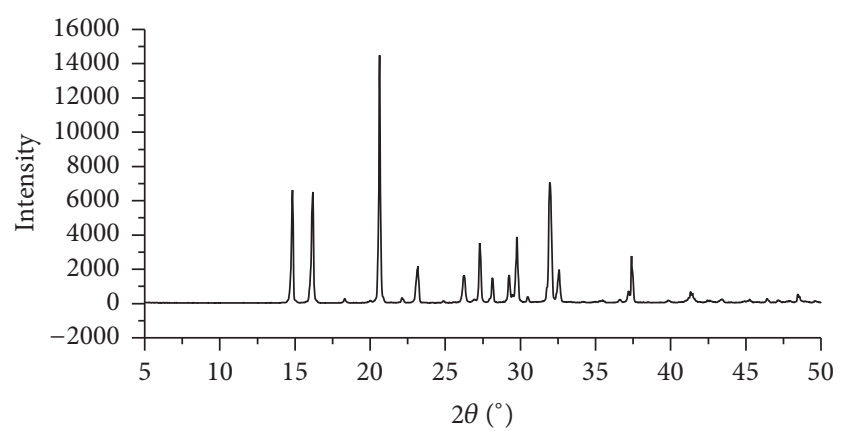

(b)

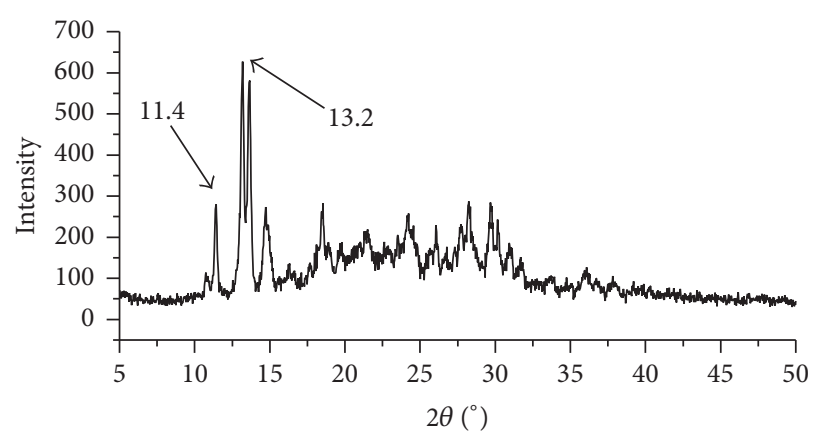

(c)

FIGURE 2: XRD patterns of explosive samples: (a) raw CL-20; (b) raw HMX; and (c) CL-20/HMX cocrystal explosive. 
TABLE 1: Assignment of the major bands of the Raman spectra of raw CL-20, raw HMX, and CL-20/HMX cocrystals.

\begin{tabular}{|c|c|c|c|c|}
\hline Assignments & CL-20 & Cocrystal & HMX & Assignments \\
\hline \multirow{4}{*}{$\mathrm{C}-\mathrm{H}$ stretching } & 3045.8 & 3043.1 & & \\
\hline & 3030.6 & 3033.3 & 3037.5 & Asymmetric $-\mathrm{CH}_{2}-$ stretch vibration \\
\hline & & & 3027.8 & \\
\hline & & 3006.9 & 2991.7 & Symmetric $-\mathrm{CH}_{2}-$ stretch vibration \\
\hline \multirow{2}{*}{$\mathrm{C}-\mathrm{N}$ stretching } & 1624.3 & & & \\
\hline & 1606.2 & 1603.4 & & \\
\hline \multirow{3}{*}{ Asymmetric $-\mathrm{NO}_{2}$ stretch vibration } & 1595.1 & 1560.4 & 1556.2 & Asymmetric $-\mathrm{NO}_{2}$ stretch vibration \\
\hline & 1577.0 & & & \\
\hline & 1559.0 & & & \\
\hline \multirow{7}{*}{$-\mathrm{NO}_{2}$ symmetric stretching } & 1382.5 & 1382.5 & & \\
\hline & 1333.9 & 1340.8 & 1347.8 & $\mathrm{~N}-\mathrm{N}$ stretch vibration + symmetric stretch vibration \\
\hline & 1308.8 & 1322.7 & & \\
\hline & 1274.1 & 1293.6 & & \\
\hline & 1260.2 & 1272.7 & & \\
\hline & 1246.3 & 1257.4 & & \\
\hline & & 1185.2 & 1189.3 & Ring stretch vibration \\
\hline \multirow[t]{2}{*}{$\mathrm{C}-\mathrm{H}$ asymmetric stretching } & 1124.0 & 1126.8 & & \\
\hline & 1086.5 & 1096.2 & & \\
\hline \multirow{3}{*}{$\mathrm{N}-\mathrm{N}$ stretching } & 1049.0 & 1050.4 & & \\
\hline & 982.3 & 990.7 & & \\
\hline & & 940.6 & 950.4 & Ring stretching \\
\hline \multirow{2}{*}{$-\mathrm{NO}_{2}$ deformation } & 854.5 & 878.1 & & \\
\hline & 832.3 & 833.7 & 832.3 & $-\mathrm{NO}_{2}$ deformation \\
\hline \multirow{2}{*}{ Ring deformation } & 368.1 & 394.5 & & \\
\hline & 343.1 & 355.6 & 359.8 & Ring deformation \\
\hline Lattice vibration & 316.7 & 315.3 & & \\
\hline \multirow{2}{*}{ Cage deformation } & 261.1 & 280.6 & & \\
\hline & 191.7 & 219.4 & & \\
\hline$-\mathrm{NO}_{2}$ deformation & 126.3 & 119.4 & & \\
\hline
\end{tabular}

showed that prepared samples did not simply mix with CL20 and HMX, but they interacted to form new cocrystals. In addition, peak of cocrystal explosive was much weaker and wider than those of raw samples, indicating nanoscale size of cocrystals from another angle.

3.3. Thermal Decomposition Characterization. Figure 3 shows DSC curves of CL-20/HMX mixture with molar ratio of $2 / 1$ and nano-CL-20/HMX cocrystal explosive at heating rate of $10 \mathrm{~K} / \mathrm{min}$. Two curves were materially different. Two peak decomposition temperatures existing were observed in CL20/HMX mixture: 250.84 (CL-20 [10]) and $284.46^{\circ} \mathrm{C}$ (HMX [11]). However, in cocrystal curve, one peak decomposition temperature was noted at $246.98^{\circ} \mathrm{C}$. Formation of CL20/HMX cocrystal was further confirmed by changing peak decomposition temperature.

3.4. Raman Analysis. Figure 4 presents Raman spectra of raw CL-20, raw HMX, and CL-20/HMX cocrystals. Table 1 lists assigned major bands of Raman spectra of samples. Figure 4 and Table 1 show that majority of peaks of CL-20 and HMX shifted markedly in cocrystal Raman spectrum. Interestingly, peaks disappeared; they represent symmetric $-\mathrm{NO}_{2}$ stretch vibration in CL-20 at $1595.1 \mathrm{~cm}^{-1}$ to $1577.0 \mathrm{~cm}^{-1}$. Similar phenomenon was observed with peaks at $3027.8 \mathrm{~cm}^{-1}$, representing asymmetric $-\mathrm{CH}_{2}-$ stretching vibration in $\mathrm{HMX}$. Symmetric $-\mathrm{CH}_{2}-$ stretch vibration shifted from $2991.7 \mathrm{~cm}^{-1}$ to $3006.9 \mathrm{~cm}^{-1}$ in $\mathrm{HMX}$. These changes can be attributed to formation of $\mathrm{C}-\mathrm{H} \cdots \mathrm{O}$ bonding between $-\mathrm{NO}_{2}$ (CL-20) and $-\mathrm{CH}_{2}-(\mathrm{HMX})$.

3.5. FT-IR Analysis. To determine whether interactions existed between CL-20 and HMX molecules in cocrystals, FTIR spectroscopy was conducted on raw CL-20, raw HMX, and CL-20/HMX cocrystals. Figure 5 presents FT-IR spectra of raw CL-20, raw HMX, and CL-20/HMX cocrystals. Table 2 lists assigned major bands of FT-IR spectra of samples. Absorptions of cocrystals are similar to those of raw materials, but some peaks of CL-20 and HMX shifted visibly, as shown in cocrystals FT-IR spectrum. For CL20/HMX cocrystals, absorptions at 1607, 1590, and $1568 \mathrm{~cm}^{-1}$, which represent asymmetric stretching of $-\mathrm{NO}_{2}$ of $\mathrm{CL}$ 20 , shifted to 1604,1576 , and $1527 \mathrm{~cm}^{-1}$, respectively, and 
TABLE 2: Assignment of the major bands of the FT-IR spectra of raw CL-20, raw HMX, and CL-20/HMX cocrystals.

\begin{tabular}{|c|c|c|c|c|}
\hline Assignments & CL-20 & Cocrystal & HMX & Assignments \\
\hline \multirow{2}{*}{$\mathrm{C}-\mathrm{H}$ stretching } & 3045 & 3033 & 3036 & $-\mathrm{CH}_{2}-$ stretching \\
\hline & 3017 & 2856 & 3027 & \\
\hline \multirow{11}{*}{ Asymmetric stretching of $-\mathrm{NO}_{2}$} & 1607 & 1604 & & \\
\hline & 1590 & 1576 & 1564 & Asymmetric stretching of $-\mathrm{NO}_{2}$ \\
\hline & 1568 & 1527 & & \\
\hline & & 1456 & 1462 & $-\mathrm{CH}_{2}-$ deformation \\
\hline & & 1432 & 1433 & \\
\hline & & 1395 & 1395 & \\
\hline & & 1331 & 1348 & \\
\hline & & 1275 & 1281 & $\mathrm{~N}-\mathrm{N}$ stretching + symmetric stretching of $-\mathrm{NO}_{2}$ \\
\hline & & 1177 & 1203 & \\
\hline & & 1144 & 1145 & $\mathrm{~N}-\mathrm{N}$ stretching + ring stretching \\
\hline & & 1096 & 1087 & \\
\hline \multirow{5}{*}{ Symmetric stretching of $-\mathrm{NO}_{2}$} & 1383 & & & \\
\hline & 1329 & & & \\
\hline & 1285 & & & \\
\hline & 1051 & 1050 & & \\
\hline & & 991 & 965 & Ring stretching \\
\hline \multirow{2}{*}{$\mathrm{C}-\mathrm{N}$ stretching } & 944 & 945 & 946 & Ring deformation \\
\hline & 884 & 882 & & \\
\hline \multirow{3}{*}{$\mathrm{C}-\mathrm{C}$ stretching } & 855 & 858 & & \\
\hline & 831 & 835 & & \\
\hline & 820 & 794 & & \\
\hline \multirow{7}{*}{$-\mathrm{NO}_{2}$ deformation } & 758 & 763 & 761 & $-\mathrm{NO}_{2}$ deformation \\
\hline & 751 & 749 & & \\
\hline & 744 & 718 & & \\
\hline & 738 & & & \\
\hline & & 655 & 658 & Ring deformation $+-\mathrm{NO}_{2}$ out-of-plane deformation \\
\hline & & 622 & 627 & \\
\hline & & 598 & 600 & \\
\hline
\end{tabular}

absorptions at 1383, 1329, and $1285 \mathrm{~cm}^{-1}$, which represent symmetric stretching of $-\mathrm{NO}_{2}$ of CL-20, shifted to 1395 , 1331 , and $1275 \mathrm{~cm}^{-1}$, respectively. Meanwhile, peaks at 3036 and $3027 \mathrm{~cm}^{-1}$, which represent $-\mathrm{CH}_{2}-$ stretching of $\mathrm{HMX}$, weakened and shifted to 3033 and $2856 \mathrm{~cm}^{-1}$, respectively. Per above analysis, we inferred that hydrogen bond interactions possibly exist between CL-20 $\left(-\mathrm{NO}_{2}\right)$ and $\mathrm{HMX}\left(-\mathrm{CH}_{2}-\right)$ molecules. Conclusion of FT-IR spectra agrees with results of Raman spectra.

3.6. Mechanical Sensitivity Characterization. Mechanical sensitivity is challenge in explosive detonation under mechanical actions, such as impact and friction. Impact and friction sensitivity tests were performed on raw CL-20, raw HMX, CL-20/HMX mixture with molar ratio of $2 / 1$, and nano-CL-20/HMX cocrystal explosives, and Table 3 provides test results. Nano-CL-20/HMX cocrystal explosive demonstrated remarkable decrease in impact and friction sensitivities in comparison with that of mixture. Drop height of nanococrystal explosive increased by $31.9 \mathrm{~cm}$ compared with CL-20/HMX mixture, and explosion probability of
TABLE 3: Mechanical sensitivities of explosive samples.

\begin{tabular}{lcc}
\hline Samples & $\mathrm{H}_{50} / \mathrm{cm}$ & $P / \%$ \\
\hline Raw CL-20 & 13.1 & 100 \\
Raw HMX & 19.6 & 84 \\
CL-20/HMX mixture & 15.4 & 96 \\
Nano-CL-20/HMX cocrystal explosive & 47.3 & 64 \\
\hline
\end{tabular}

friction was $20 \%$ lower than that of raw HMX. Result suggests that nano-CL-20/HMX cocrystal explosive is difficult to detonate under impact and friction conditions.

\section{Conclusions}

Spray drying method was used to prepare nano-CL-20/HMX cocrystal explosive in 2/1 molar ratio. XRD and DSC patterns revealed that cocrystal explosive was not the intimate mixture of CL-20/HMX. Raman and FT-IR spectra imply that formation of CL-20/HMX cocrystals originates from $\mathrm{C}-\mathrm{H} \cdots \mathrm{O}$ hydrogen bonding between $-\mathrm{NO}_{2}(\mathrm{CL}-20)$ and 


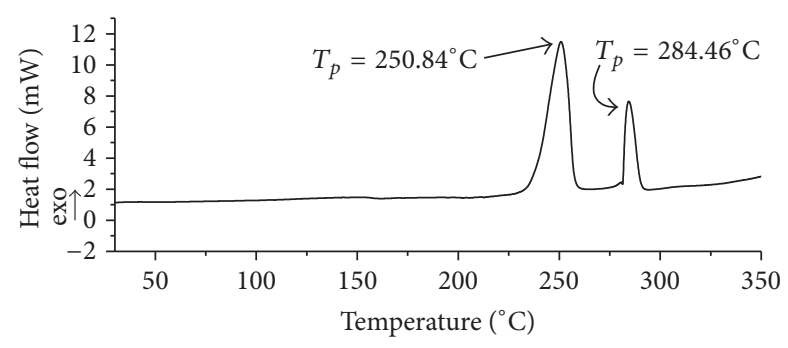

(a)

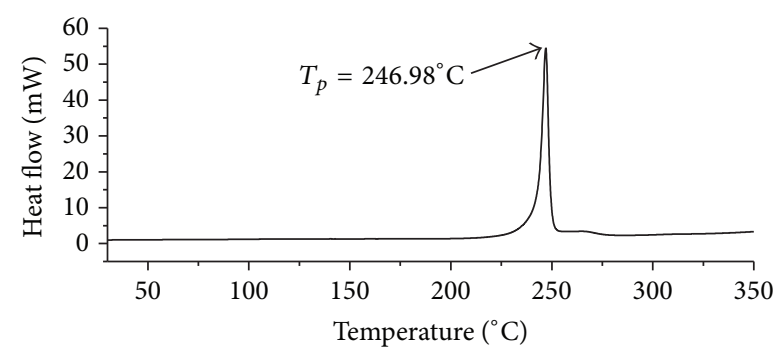

(b)

FIGURE 3: DSC curves of explosive samples at heating rates of $10 \mathrm{~K} / \mathrm{min}$ : (a) CL-20/HMX mixture with molar ratio of $2 / 1$ and (b) nano-CL-20/HMX cocrystal explosive.

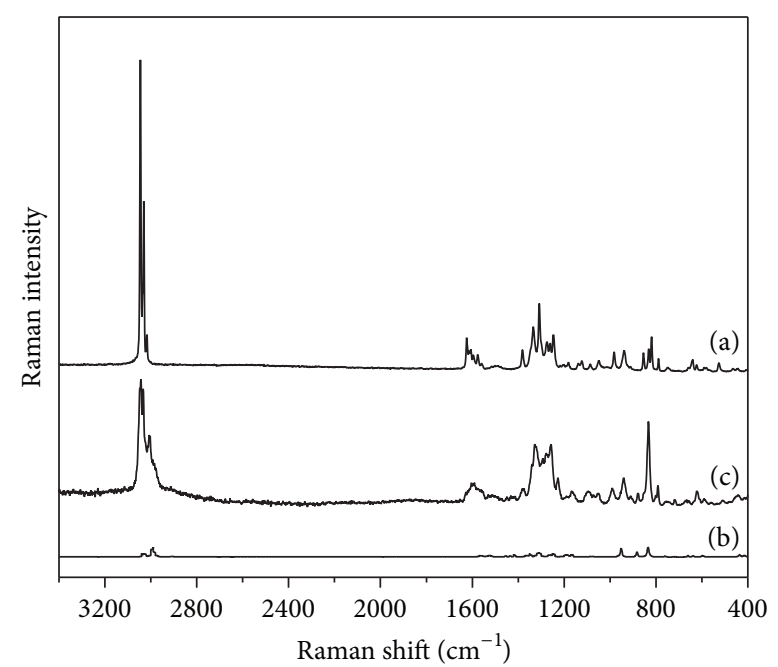

FIGURE 4: Raman spectra of explosive samples: (a) raw CL-20; (b) raw HMX; and (c) CL-20/HMX cocrystals.

$-\mathrm{CH}_{2}-$ (HMX). CL-20/HMX cocrystals are plate-like in shape with thicknesses below $100 \mathrm{~nm}$. These tiny cocrystals do not disperse individually but rather agglomerate into microparticles ranging from $0.5 \mu \mathrm{m}$ to $5 \mu \mathrm{m}$ in size. Peak decomposition temperature of cocrystal explosives is $246.98^{\circ} \mathrm{C}$, which is $3.86^{\circ} \mathrm{C}$ lower than that of CL-20. Compared with that of HMX, nanococrystals manifested significant decrease in impact and friction sensitivities, drop height increased by $141 \%$, and friction probability reduced by $20 \%$. Nano-CL-20/HMX cocrystal explosive exhibits insensitivity to mechanical action.

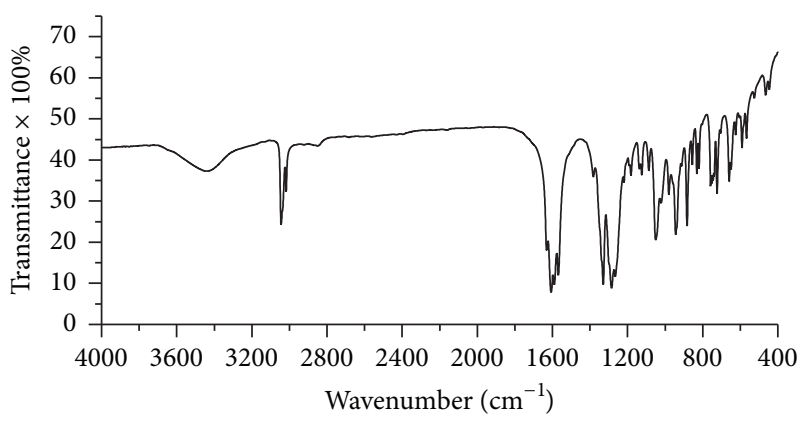

(a)

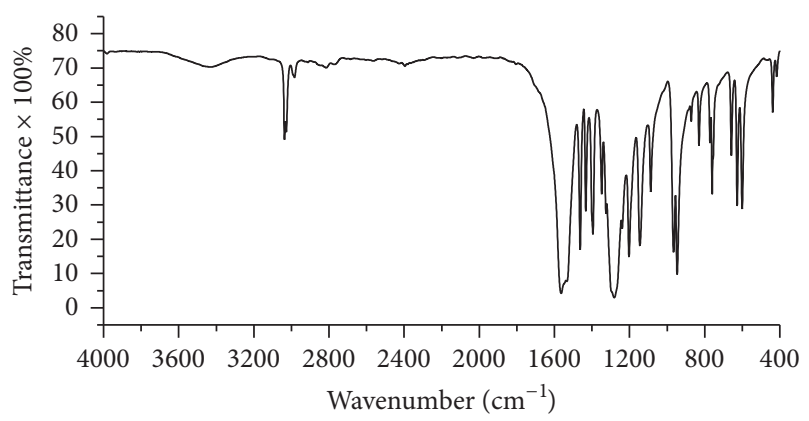

(b)

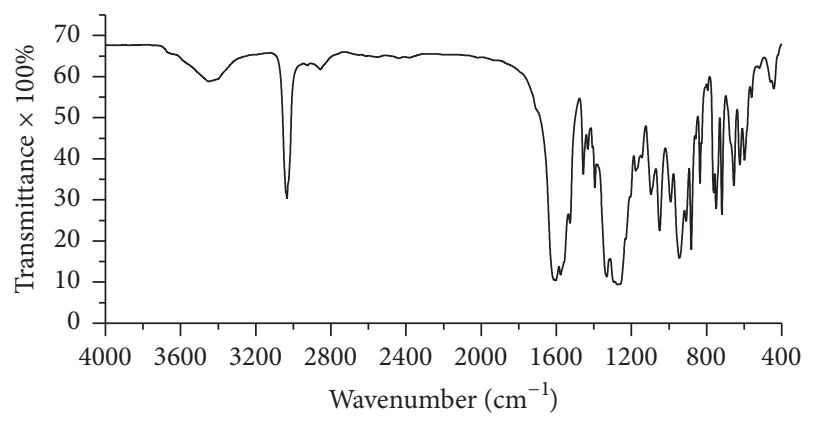

(c)

FIGURE 5: FT-IR spectra of explosive samples: (a) raw CL-20; (b) raw HMX; and (c) CL-20/HMX cocrystals.

\section{Competing Interests}

The authors declare that there is no conflict of interests regarding the publication of this paper.

\section{Acknowledgments}

This work was funded by the Graduate Education Innovation Project of Shanxi Province (no. 2016BY119) and the 13th Graduate Student of Science and Technology in North University of China (no. 20161325).

\section{References}

[1] S. Yu and H. Li, "A novel melt cast composite booster formulation based on DNTF/TNT/GAP-ETPE/Nano-HMX," Journal of Chemistry, vol. 2016, Article ID 6521913, 5 pages, 2016.

[2] C. An, F. Li, J. Wang, and X. Guo, "Surface coating of nitroamine explosives and its effects on the performance of composite 
modified double-base propellants," Journal of Propulsion and Power, vol. 28, no. 2, pp. 444-448, 2012.

[3] U. R. Nair, G. M. Gore, R. Sivabalan, C. N. Divekar, S. N. Asthana, and H. Singh, "Studies on advanced CL-20based composite modified double-base propellants," Journal of Propulsion and Power, vol. 20, no. 5, pp. 952-955, 2004.

[4] K. Liu, G. Zhang, Z. Q. Chen, J. Y. Luan, and M. Xu, "Research progress of cocrystal energetic materials," Chemical Analysis and Meterage, vol. 23, no. 5, pp. 139-142, 2014.

[5] O. Bolton, L. R. Simke, P. F. Pagoria, and A. J. Matzger, "High power explosive with good sensitivity: a 2:1 cocrystal of CL20:HMX," Crystal Growth and Design, vol. 12, no. 9, pp. 43114314, 2012.

[6] Z. Liu, Q. Wu, W. Zhu, and H. Xiao, "Insights into the roles of two constituents CL-20 and HMX in the CL-20:HMX cocrystal at high pressure: a DFT-D study," RSC Advances, vol. 5, no. 43, pp. 34216-34225, 2015.

[7] T. Sun, J. J. Xiao, Q. Liu, F. Zhao, and H. M. Xiao, "Comparative study on structure, energetic and mechanical properties of a $\varepsilon$-CL-20/HMX cocrystal and its composite with molecular dynamics simulation," Journal of Materials Chemistry A, vol. 2, no. 34, pp. 13898-13904, 2014.

[8] A.-B. Zhang, Y.-F. Cao, Y. Ma, Y.-Q. Zhu, and C.-Y. Zhang, "Theoretical research on packing structures of energetic cocrystals," Chinese Journal of Energetic Materials, vol. 23, no. 9, pp. 848857, 2015.

[9] S. R. Anderson, D. J. Am Ende, J. S. Salan, and P. Samuels, "Preparation of an energetic-energetic cocrystal using resonant acoustic mixing," Propellants, Explosives, Pyrotechnics, vol. 39, no. 5, pp. 637-640, 2014.

[10] C. An, B. Yu, H. Li, W. Guo, and J. Wang, "Preparation and characterization of ultrafine $\varepsilon$-hexanitrohexaazaisowurtzitane particles," International Journal of Energetic Materials and Chemical Propulsion, vol. 14, no. 4, pp. 295-306, 2015.

[11] C. An, H. Li, W. Guo, X. Geng, and J. Wang, "Nano cyclotetramethylene tetranitramine particles prepared by a green recrystallization process," Propellants, Explosives, Pyrotechnics, vol. 39, no. 5, pp. 701-706, 2014.

[12] X. Shi, J. Wang, X. Li, and C. An, "Preparation and properties of HMX/Nitrocellulose nanocomposites," Journal of Propulsion and Power, vol. 31, no. 2, pp. 757-760, 2015.

[13] T. Naya and M. Kohga, "Influences of particle size and content of HMX on burning characteristics of HMX-based propellant," Aerospace Science and Technology, vol. 27, no. 1, pp. 209-215, 2013.

[14] T. Naya and M. Kohga, "Influences of particle size and content of RDX on burning characteristics of RDX-based propellant," Aerospace Science and Technology, vol. 32, no. 1, pp. 26-34, 2014.

[15] D. Spitzer, B. Risse, F. Schnell, V. Pichot, M. Klaumünzer, and M. R. Schaefer, "Continuous engineering of nano-cocrystals for medical and energetic applications," Scientific Reports, vol. 4, article 6575, 2014.

[16] B. Gao, D. Wang, J. Zhang et al., "Facile, continuous and largescale synthesis of CL-20/HMX nano co-crystals with highperformance by ultrasonic spray-assisted electrostatic adsorption method," Journal of Materials Chemistry A, vol. 2, no. 47, pp. 19969-19974, 2014.

[17] H. Qiu, R. B. Patel, R. S. Damavarapu, and V. Stepanov, "Nanoscale 2CL-20.HMX high explosive cocrystal synthesized by bead milling," CrystEngComm, vol. 17, no. 22, pp. 4080-4083, 2015.
[18] A. Alhalaweh and S. P. Velaga, "Formation of cocrystals from stoichiometric solutions of incongruently saturating systems by spray drying," Crystal Growth and Design, vol. 10, no. 8, pp. 3302-3305, 2010.

[19] A. Alhalaweh, W. Kaialy, G. Buckton, H. Gill, A. Nokhodchi, and S. P. Velaga, "Theophylline cocrystals prepared by spray drying: physicochemical properties and aerosolization performance," AAPS PharmSciTech, vol. 14, no. 1, pp. 265-276, 2013.

[20] J.-Y. Wang, H.-Q. Li, C.-W. An, and W.-J. Guo, "Preparation and characterization of ultrafine CL-20/TNT cocrystal explosive by spray drying method," Chinese Journal of Energetic Materials, vol. 23, no. 11, pp. 1103-1106, 2015.

[21] H. Li, C. An, W. Guo, X. Geng, J. Wang, and W. Xu, "Preparation and performance of nano HMX/TNT cocrystals," Propellants, Explosives, Pyrotechnics, vol. 40, no. 5, pp. 652-658, 2015.

[22] Chinese Commission of Science and Technology and Industry for National Defense, "Explosive test method," Chinese National Military Standard GJB/772A-97, 1997. 

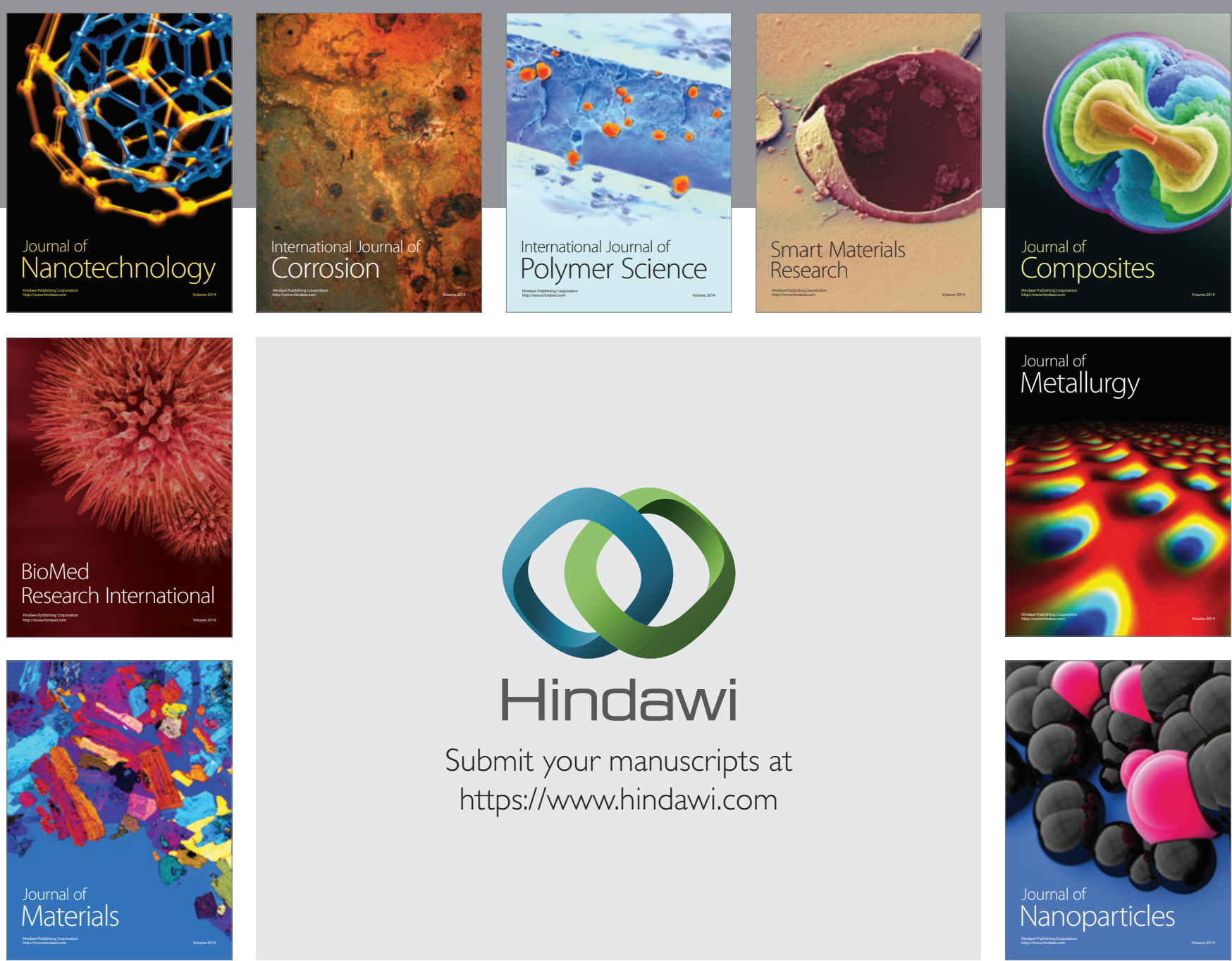

\section{Hindawi}

Submit your manuscripts at

https://www.hindawi.com

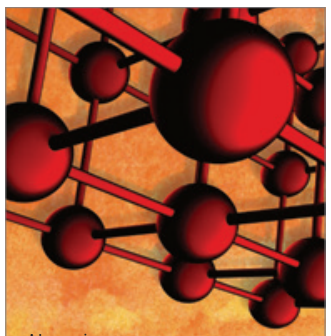

Materials Science and Engineering
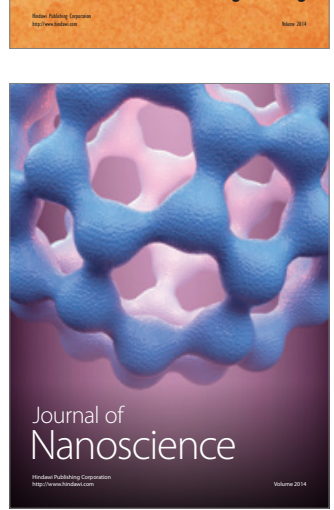
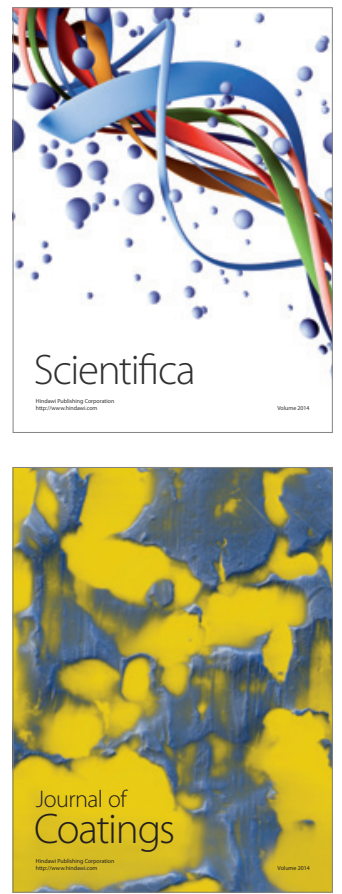
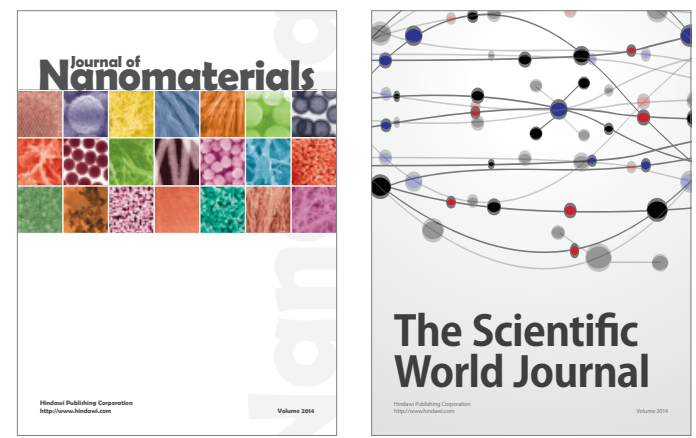

The Scientific World Journal
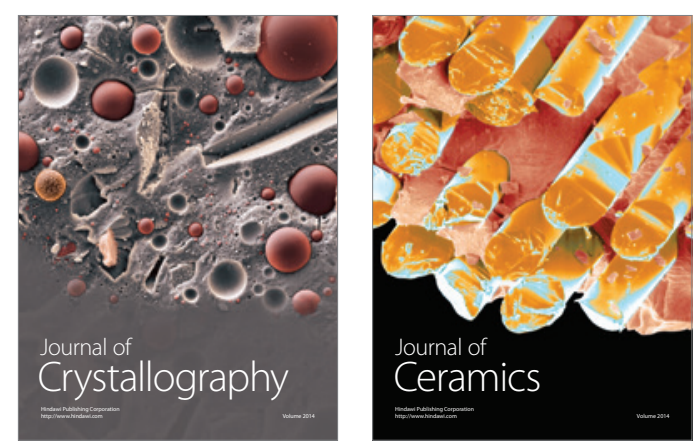
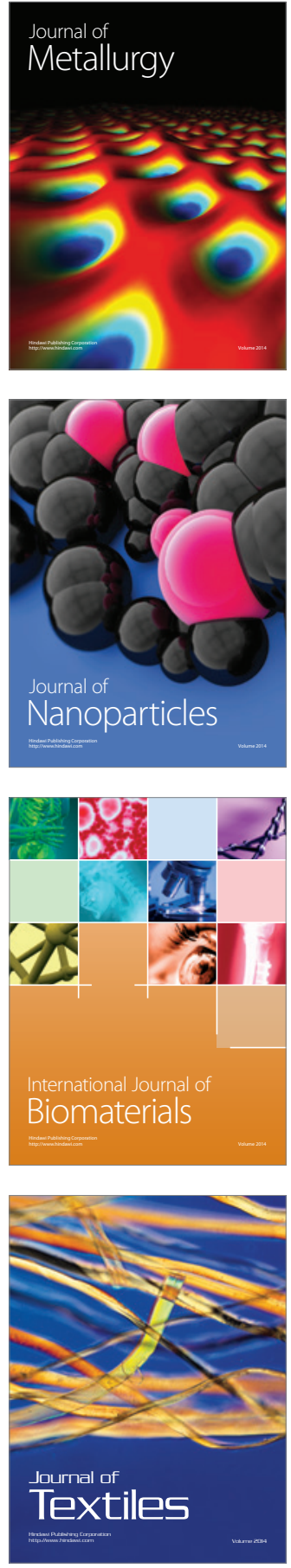